\title{
Notícias da pré-escola no Distrito Federal: apontamentos de Yvonne Jean (1960-1964) ${ }^{1}$ \\ Preschool news in the Federal District: Yvonne Jean's notes (1960-1964)
}

\author{
Etienne Baldez L. Barbosa*
}

\begin{abstract}
RESUMO
Em abril de 1960 foi inaugurada a nova capital do Brasil, que continuou com obras posteriores, mas já tendo concretizado sua identidade de ser um símbolo de modernidade arquitetônica no país. Diversos brasileiros, acompanhados ou não de suas famílias, rumaram ao Distrito Federal, seja para serviços privados ou públicos. Nesse sentido, novas relações e vínculos familiares se constituíram e, com eles, o nascimento de crianças, fora as que vieram com os pais. Este trabalho investiga, pela ótica da jornalista Yvonne Jean, a organização dos jardins de infância, locais onde os pequenos, entre quatro e seis anos, recebiam educação institucionalizada. O recorte temporal compreende o ano da inauguração dos primeiros Jardins de Infância (1960), a chegada de Yvonne Jean à Brasília, com a publicação de sua coluna no jornal, com notícias sobre a educação (1962) e, ao final, o ano em que a jornalista é presa, acusada de compactuar com os ideais comunistas (1964).

Palavras-chave: Jardins de Infância. Distrito Federal. Yvonne Jean.
\end{abstract}

\begin{abstract}
In April 1960, the new capital of Brazil was inaugurated, which was followed by subsequent constructions, although it already had established its identity as a symbol of architectural modernity in the country. Several Brazilians, accompanied or not by their families, headed for the Federal District, whether
\end{abstract}

1 O presente artigo é uma publicação decorrente do projeto de pesquisa "Jardins de Infância no Distrito Federal: uma história da sua institucionalização (1960 a 1980)", financiado com recursos do Decanato de Pesquisa e Inovação da Universidade de Brasília (Edital 04/2019), ao qual registro agradecimento.

*Universidade de Brasília. Faculdade de Educação. Brasília, Distrito Federal, Brasil. E-mail: blb.etienne@gmail.com - https://orcid.org/0000-0001-6780-3148 
for private or public services. In this sense, new family relationships and bonds were formed and, with them, the birth of children, apart from those who came with their parents. This paper investigates, from the perspective of the journalist Yvonne Jean, the organization of kindergartens, places where little ones, between four and six years old, received institutionalized education. The time frame comprises the year of the inauguration of the first kindergartens (1960), the arrival of Yvonne Jean in Brasília, with the publication of her newspaper column, with news about education (1962) and, at the end, the year in that the journalist is arrested, accused of colluding with communist ideals (1964).

Keywords: Kindergarten. Federal District. Yvonne Jean.

Há seis décadas foi organizada oficialmente a estrutura da pré-escola no Distrito Federal (1960), com a instituição de Jardins de Infância, destinados à educação de crianças entre quatro e seis anos de idade. Alguns caminhos podem ser empreendidos na busca pela história desses Jardins de Infância, ainda pouco visitada pela produção científica, e, um deles, pode ser partir para os indícios ${ }^{2}$ de sua configuração, por meio de fontes diversas, como a coluna escrita pela jornalista Yvonne Jean, no jornal Correio Braziliense (1962 a 1964)3.

Trabalhando com a trajetória dessa jornalista, Ana Paula Teixeira (2018) demonstra que seu nome era Yvonne Silberfeld, mas adotou o Jean para assinar suas colunas em jornais e revistas no Brasil, país a que chegou em 1940, aos 29 anos, fugindo com sua família da Bélgica, do regime nazista. Formada em Histologia, no Brasil se tornou jornalista, escritora e tradutora. Nas duas primeiras décadas que aqui esteve, colaborou com os principais jornais do Rio de Janeiro e, em 1962, mudou-se para Brasília, junto com seu marido, o advogado Abelardo da Fonseca, em resposta ao convite feito por Darcy Ribeiro, para atuar no Centro de Extensão Cultural da Universidade de Brasília (TEIXEIRA, 2018, p. 17-18).

É pertinente relembrar que Brasília foi inaugurada no dia 21 de abril de 1960 e o seu desenho foi pensado pelo arquiteto Lúcio Costa, vencedor do concurso de 1956, que contou com a participação de vinte e seis projetos para a nova capital do país. Como demonstra Aline Braga (2011), grande foi a influência de Le Corbusier nos planos apresentados e, apesar de muitas diferenças, "a

2 Coadunados aqui com o paradigma indiciário de Carlo Ginzburg (1990).

3 A coluna começa em 1962, intitulada "Esquina de Brasília" e, neste mesmo ano, muda para "O Ensino Dia a Dia". Em 1965, nova reconfiguração é feita na nomenclatura, voltando a se chamar "Esquina de Brasília". 
maioria dos projetos separava as atividades de habitação, circulação, trabalho e lazer" (BRAGA, 2011, p. 31). Após a escolha do projeto para o Plano Piloto da nova capital federal, entre as inúmeras organizações demandadas para a sua efetivação, estava a configuração do sistema de ensino, que deveria estar articulado com a estrutura pensada. Nesse sentido, foi criado o Plano das Construções Escolares de Brasília, publicado em 1961, por Anísio Teixeira, que, à época, exercia a função de diretor do Instituto Nacional de Estudos Pedagógicos (INEP - 1952-1964).

O Plano das Construções Escolares de Brasília foi engendrado coletivamente, contando com o Ministério da Educação e Cultura e a Companhia Urbanizadora da Nova Capital do Brasil (NOVACAP). Como disposto no referido, "tal programa constitui, assim, menos um desafio aos arquitetos de Brasília do que um oferecimento de ampla liberdade de concepção para os novos e complexos conjuntos escolares", sendo, portanto, um "conjunto de edifícios, com funções diversas e considerável variedade de forma e de objetivos, a fim de atender a necessidades específicas" (TEIXEIRA, 1961, p. 195). Samira Chahin (2018) reforça que o Plano é o "resultado de um otimismo coletivo, talvez ingênuo, de intelectuais empenhados em fazer a mudança da capital algo maior que um 'traçado perfeito', somado à construção de edifícios modernos, ponte e estradas pavimentadas" (CHAHIM, 2018, p. 14). Na descrição do plano, está a justificativa de que ele tinha como propósito "abrir a oportunidade para a capital federal oferecer à nação um conjunto de escolas que pudessem constituir exemplo e demonstração para o sistema educacional do país" e isso considerando que "as necessidades da civilização moderna cada vez mais impõem obrigações à escola, aumentando-lhes as atribuições e funções" (TEIXEIRA, 1961, p. 195).

A ideia central do Plano das Construções Escolares de Brasília era romper com um sistema educacional estático, permitindo uma democratização no acesso das crianças, independentemente da classe social e econômica, que frequentariam as mesmas instituições; sem contar que se integrava, no movimento de sua configuração, em uma perspectiva da modernidade no período (PEREIRA; ROCHA, 2011; SILVA, 1985). Destaca-se que nos anos posteriores à Segunda Guerra Mundial se constituiu um movimento de democracia liberal e de um contexto nacional desenvolvimentista, quando se propunham atitutes individuais e coletivas inovadoras, mediante os padrões existentes na sociedade brasileira.

No plano político, é interessante relembrar que o início da década de 1960 no Brasil foi de mudanças, com a eleição e vitória de Jânio Quadros para presidente. O país vivia uma crise econômica, a inflação estava em alta, assim como a dívida externa. Era um período de recessão econômica, ausência de investimentos em educação e saúde, congelamento de salários e medidas impopulares e ineficientes. Foi todo um contexto que contribuiu para uma grande 
oposição ao presidente (trabalhadores urbanos, empresários, classe média e militares), também pelas críticas que fez ao governo de Juscelino Kubitschek, conquistando opositores no Senado e na Assembleia Legislativa.

Em agosto de 1961 Jânio Quadros renunciou, iniciando o governo de João Goulart (1961-1964), ainda que o partido liberal conservador União Democrática Nacional (UDN) tenha feito uma manobra para impedir a sua posse, que foi, a princípio, com poderes limitados. Foi um período de instabilidade política, inflação, recessão econômica e aumento de greves. João Goulart foi acusado de querer implantar um governo trabalhista e socialista no Brasil, principalmente quando se consideraram as reformas de base propostas, sendo implicado como subversivo e deposto do cargo de presidente. Nesse sentido, em abril de 1964, foi instalada a Ditadura Militar Brasileira (FERREIRA; GOMES, 2014; FICO, 2014; FERREIRA, 2019).

Em meio a reconfigurações políticas e econômicas, tem-se uma nova capital, que promoveu uma imigração para a Região Centro-Oeste do país, não somente de adultos, como também de crianças que vinham com a família ou que em Brasília nasceram. É para os Jardins de Infância que o presente estudo se volta, local onde as crianças recebiam o ensino institucionalizado. Mais do que identificar sua organização por meio da documentação oficial, a intenção aqui é compreendê-los por meio da circulação de notícias, vinculadas na página do jornal Correio Braziliense, de autoria da jornalista Yvonne Jean. O recorte temporal compreende o ano da inauguração dos primeiros Jardins de Infância (1960), a chegada de Yvonne Jean à Brasília, com a publicação de sua coluna no jornal, com notícias sobre a educação (1962) e, ao final, o ano em que a jornalista é presa, acusada de compactuar com os ideais comunistas (1964). Ana Paula Teixeira (2018, p. 94) pontua que: "no manuscrito de 'A Chave', YJ explica que escreve em julho de 1964 de uma prisão onde conseguira o benefício de uma máquina de escrever, mas que ficara presa arbitrariamente por dias sem processo ou previsão de saída. Fora levada para um interrogatório e ficara detida". A autora acrescenta que "mais tarde, YJ foi processada e presa em outro caso, inaugurado em 1969, cuja sentença saiu em 1971 [...]" (TEIXEIRA, 2018, p. 99). Em sua coluna "Visto, lido e ouvido", também do jornal Correio Brasiliense, o jornalista Ari Cunha escreve:

Eu queria que o general Sousa Aguiar soubesse o que está acontecendo na polícia da PE, onde estão os presos políticos. Yvonne Jean, nossa companheira de jornal, responsável pela Educação e Ensino, está presa há uma semana e, por maior que tem sido o esforço dos seus companheiros, ainda não foi possível uma visita (CUNHA, 1964, p. 3). 
Posteriormente, resolvida a questão judicial, a coluna de Yvonne Jean continuou a ser por ela escrita e publicada no jornal. O acompanhamento de sua coluna demonstra algumas mudanças nos temas abordados, sendo dada prioridade inicialmente para notas relacionadas com a Universidade de Brasília, com o Ensino Secundário, com o Ensino Primário até chegar no Ensino PréPrimário e na alternância entre eles. O olhar para sua coluna é feito a partir de uma problematização: que questões sobre os jardins de infância são evidenciadas por Yvonne Jean? Na busca por essa resposta, a intenção é passar pelas práticas voltadas para a educação da criança pequena.

\section{Jardins de Infância na capital do Brasil: a pré-escola instituída}

Antes da inauguração de Brasília, em 1959, o Departamento de Educação e Difusão Cultural, da Companhia Urbanizadora da Nova Capital do Brasil, ficou com a responsabilidade pela organização e proposição de Jardins de Infância, bem como pela seleção e orientação de professores(as), de acordo com a Portaria $n^{\circ}$ 103/B, de 30 de abril de 1959 (BRASÍLIA, 1981). No final daquele ano, foi instituída a Comisão de Administração do Sistema Educacional de Brasília (CASEB), responsável pela construção e manutenção do sistema de ensino, por meio do Decreto ${ }^{\circ}$ 47.472, de 22 dezembro de 1959 (BRASÍLIA, 1981). No início do ano seguinte, foi criada a Fundação Educacional do Distrito Federal (FEDF), pelo Decreto nº 47.832-A, de 4 de maço de 1960 (BRASÍLIA, 1981). Dentre os objetivos da referida Fundação, estavam "estabelecer toda colaboração ao poder público no cumprimento dos programas adotados para o desenvolvimento do ensino no Distrito Federal" e "criar, instalar e manter estabelecimentos de ensino elementar, pré-primário, primário, complementar, emendativo e de iniciação profissional, para crianças, para adolescentes e adultos", segundo o Estatuto da FEDF, de 2 de julho de 1960 (BRASÍLIA, 1981).

A publicação de portarias, decretos e do estatuto da Fundação, os quais contemplavam a pré-escola no Distrito Federal, indica a preocupação com a educação institucionalizada da criança pequena, em um espaço educativo. Ao tomar as três décadas anteriores, Sonia Kramer (1992) demonstra uma discussão e intencionalidade na educação da criança que já estava sendo construída por diversos órgãos vinculados à saúde, à educação, à assistência social e à iniciativa privada. Como aponta a autora, o próprio Departamento Nacional da Criança, criado em 1940, tinha uma tendência médico-higienista (combate à desnutrição; vacinação; obras de hospitais e maternidades, etc.) e individual assistencialista (programas de fortalecimento familiar e educação sanitária). 
Considerando a questão educacional, o Departamento Nacional da Criança teve a preocupação com a recreação das crianças, que seria realizada em Centros de Recreação, em áreas anexas às Igrejas, pelo Programa de Proteção ao Pré-Escolar. Contudo, como a autora demarca, havia uma fragmentação no atendimento e nas políticas voltadas à infância, muitas vezes precarizando as ações, havendo "uma ênfase acentuada na proteção da saúde, [em que] progressivamente as preocupações se voltaram para a assistência social e daí para a educação", mas sem que uma acontecesse conjuntamente com a outra, ocorrendo sempre "uma ramificação gradativa do atendimento à infância" (KRAMER, 1992, p. 87).

Quando se visita os jornais brasileiros das décadas de 1950 e 60, observase uma efervescência em torno da discussão dos kindergartens. De São Paulo, Vicente Peixoto escreve para a Revista do Professor sobre o problema do ensino primário e aponta, entre as soluções, a criação de Jardins de Infância, seguindo o que a professora Nair Lacerda relatou da visita aos Estados Unidos:

Desde o jardim da infância, verdadeiras joias de gosto dentro das escolas primárias e abundantes ao ponto de terem toda uma linha de profissionais, que cuidam exclusivamente da sua organização, até o fim da "senior high school", que corresponde ao nosso ginásio [...]. Como ganharia em eficiência e rendimento, a nossa escola primária, se, antecedendo o seu curso, houvesse em nossos grupos escolares o que se convencionou chamar, e mui acertadamente, "jardim de infância", o "kindergarten", maravilhosa criação do imortal Froebel! Seria, por assim dizer, o primeiro entrelaçamento, isto é, o da escola pré-primária com a primária (LACERDA, 1954, p. 9).

No trecho anterior, o professor faz a defesa da criação de Jardins de Infância em benefício do desempenho das crianças na próxima fase, o primário. Para legitimar sua solução, lança mão do kindergarten dos Estados Unidos, como modelo. Como explica Moysés Kuhlmann Jr. (2007, p. 14), "a difusão da proposta froebeliana percorre caminhos que vão da longa tradição da modernidade" e, por meio de associações, congressos e indivíduos intelectuais, as propostas "se propagaram por diferentes contextos nacionais e sociais".

O acompanhamento nos jornais permite indicar que estava em evidência o kindergarten americano baseado na concepção de Friedrich Froebel, como na notícia "Revelações sobre o Sistema Norte Americano" (REVELAÇÕES..., 1953 , p. 12). Se no referido país os Jardins de Infância surgem segundo o modelo froebeliano, nas décadas de 1950 e 60 se aproximavam mais ao modelo 
montessoriano. Em um livro sobre o Jardim de Infância, traduzido e publicado no Brasil em 1967, a informação é sobre o pensamento de John Dewey, que reconhecia a importância de pensar o presente e o futuro da criança pequena com implicações educativas e com programas criados por professoras com formação competente: "a educação não é apenas uma preparação para o que virá, é também o enriquecimento e a interpretação do presente" (FOSTER; HEADLEY, 1967, p. 49).

Lívia Vieira (1999) demarca que os jardins de infância ou escolas infantis, pensando a vinculação com o campo educativo, expandiram-se no Brasil paulatinamente até a década de 1970. Todavia, as classes chamadas de pré-primário surgem já na década de 1950, anexas às escolas que tinham ensino primário. Tanto os jardins, escolas infantis ou pré-primário acabavam contribuindo não somente para a socialização da criança, como também para a sua preparação para o ensino elementar (VIEIRA, 1999, p. 29).

Voltando à Brasília, antes mesmo da inauguração da capital, foi criado um Jardim de Infância anexo à Escola Dr. Ernesto Silva, em 1958. Segundo os "Dados históricos do ensino oficial do Distrito Federal" (FEDF), "nessa ocasião a rede de ensino oficial já contava com 626 alunos, 18 professores, 2 escolas e 1 Jardim de Infância" e, em 1960, "contava com um corpo docente de 67 professores, 12 escolas primárias, com 2.134 alunos e 2 Jardins de Infância" (BRASÍLIA, 1981, p. xxix). No perído em que Yvonne Jean escreveu sua coluna no jornal Correio Braziliense, existiam seis Jardins de Infância, que eram: o Jardim de Infância 21 de Abril (inaugurado em fevereiro de 1960), Jardim de Infância da Super Quadra Sul 208 (inaugurado em maio de 1960), Jardim de Infância da Super Quadra Sul 108 (inaugurado em agosto de 1960), Jardim de Infância da Super Quadra Sul 114 (inaugurado em fevereiro de 1962), Jardim de Infância da Super Quadra Norte 404 (inaugurado em fevereiro de 1963) e Jardim de Infância do Cruzeiro Velho (inaugurado em 1963) (BRASÍLIA, 1972, p. 10). Além desses, haviam seis classes de Jardins de Infância que funcionavam anexas às Escolas Classes: duas classes anexas à Escola Classe do Setor Habitacional Individual Sul e quatro salas na Escola Classe Sargento Lima (BRASÍLIA, 1972, p. 10). É essa rede constituída que acompanharemos no relato da referida jornalista. 


\section{A educação da infância nas páginas do jornal}

Quando acompanhamos a escrita da jornalista no jornal Correio Braziliense, ao longo dos anos, é possível percebê-la como uma pessoa que levanta críticas quanto à oferta de vagas, que aponta iniciativas louváveis nas práticas pedagógicas desenvolvidas nos jardins de infância e que levanta algumas frentes a favor dessa etapa de educação da criança pequena em Brasília. Mas, de onde vem essa legitimidade para falar de educação conferida a Yvonne Jean?

Rafael Pereira da Silva (2019, p. 174) retoma brevemente fragmentos da vida de Yvonne Jean e informa que "não saberia dizer por que meios ela conseguiu um expediente" no Ministério da Educação e Saúde, no Serviço de Neurobiologia do Serviço Nacional de Doenças Mentais, como técnica em neuropatologia, tradutora de artigos científicos, redatora de trabalhos histológicos, até 1946. O autor pontua sobre a inserção de Yvonne Jean na capital e sociedade carioca:

A princípio, uma hipótese que explicaria o rápido acesso de Yvonne às suas atividades profissionais seria o fato de ser vista não como refugiada, antes como uma recém-chegada ou imigrante, cujas características - branca, europeia, francófona, culta, poliglota e abastada - poderiam ser uma boa porta de entrada nos meios políticos e culturais.[...]. A aceitação de Yvonne na elite letrada local talvez se explique por meio de sua educação formal como mulher judia. Referências importantes como Michelle Perrot e Nancy Green registraram que o contexto de grandes migrações e perseguições, entre o final do século XIX e as primeiras décadas do século XX, foi decisivo para uma maior participação das mulheres no espaço público, contraponto à imagem da mulher confinada. [...]. Concomitante ao serviço público, portanto, a escritora passou a frequentar os principais círculos do jornalismo brasileiro, obtendo espaço na redação de veículos cariocas e paulistas como o Diário de Notícias, Correio da Manhã, Folha da Manhã, Folha da Tarde, Estadão, entre outros (SILVA, 2019, p. 175-176).

Seguindo a análise de Silva (2019), a formação de Yvonne Jean em diversos países - como Itália, Holanda, Alemanha, Áustria, Suíça, Inglaterra -, bem como seu capital cultural, garantiram sua inserção rápida na sociedade carioca, o que possibilitou o desdobramento profissional, até a função de jornalista, abordando temáticas relacionadas com arte, cultura, questões femininas, cotidiano, entrevistas, e a que nos interessa aqui, educação. 
Olhar para os jornais na década que antecede sua chegada à nova capital do país é identificar quais elementos educativos já discutia e que podem ter sido aguçados na sua atuação em Brasília, considerando a educação infantil. É possível destacar como um ponto forte a sua inserção nas questões envolvendo a literatura infantil. Seu livro "Os tucanos da floresta" é indicado na seção "Forme sua Biblioteca", ao lado de outras produções voltadas para crianças ou professoras. Sobre a obra é descrito que "o livro é escrito em estilo agradável e linguagem simples, o que o torna bem acessível às crianças" (FORME..., 1955 , p. 19). As outras obras que permitem uma relação com o universo infantil ou com o das docentes são: "Dramatizações escolares", de Zulmira de Queiroz Breiner; "Janela para os cegos: Luiz Braille”, de J. Alvim Kugelmass; "Brinquedos para dias de chuva", de Caroline Horowitz; álbum de figurinhas "Zoo Fantástico"; "Memórias de Sherlock Holmes", "O cão dos Baskervilles", "O vale do terror", de Conan Doyle; "Elementos de psicologia", de Iva Waisberg Bonow; "Pedacinhos de mim", de Nabor Fernandes e "O Aleijadinho", de R. A. Freudenfeld.

Outro livro infantil de sua autoria já havia comparecido como uma das indicações literárias voltadas para crianças: "Joãozinho no País das Sobremesas", referenciado também pelas "belas ilustrações de Louis Specker" (PUBLICAÇÕES INFANTIS, 1951, p. 1). No programa para crianças chamado "Reino da Alegria", Yvonne Jean era uma das redatoras (ONTEM E HOJE, 1955). No concurso sobre Aspectos da Literatura Infantil, que considerava as produções literárias destinadas à educação alimentar das crianças, Yvonne Jean comparece como uma das "figuras representativas do mundo oficial e dos meios intelectuais" que estavam presentes (ASPECTOS..., 1952, p. 2).

Yvonne Jean não somente era referenciada como uma intelectual nos jornais, como também participava de eventos com tal característica destacada. Antes mesmo de imaginar que moraria e trabalharia no Centro-Oeste, ela esteve como participante do "Congresso Nacional de Intelectuais em Goiás", realizado em janeiro de 1954 (CONGRESSO NACIONAL..., 1953, p. 3). Ser denominada como intelectual aqui pode significar que ela era percebida como uma pessoa que produzia ideias relacionadas com questões infantis e que acabavam por repercutir em propostas voltadas para a educação da criança menor de seis anos. Como descrito por Moysés Kuhlmann Jr. (2010, p. 87), os intelectuais são considerados enquanto categoria social e histórica e, portanto, compreende-se que "as representações, os discursos e os artefatos simbólicos que configuram a realidade são produzidos e imaginados por pessoas reais, e têm efeito sobre a vida das pessoas reais, que nascem, crescem, amam, sofrem e morrem" (KUHLMANN JR., 2010, p. 87). 
Ainda relacionando sua atuação com as questões infantis, foi noticiado no jornal Diário Carioca que Yvonne Jean era vice-presidente da "I Assembleia Nacional da Mulher", que discutiu mortalidade infantil apresentando-se o fato de que "mais da metade das crianças que nascem atualmente no Brasil morrem antes de atingir os 5 anos", e que, entre os sete temas debatidos, estavam "creche" e "jardim de infầncia" (I ASSEMBLEIA..., 1952, p. 12). Na primeira sessão do referido evento ela tratou do cartão de prioridade que deveria ser dado à mulher gestante, para que obtivesse atendimento médico, e abordou "também a questão da merenda escolar nos estabelecimentos de ensino" (MAIS..., 1952, p. 12).

Meses antes, o periódico O Momento Feminino tratou da Conferência Internacional de Defesa da Infância, realizada em Viena, entre os dias 12 e 16 de abril, informando que Yvonne Jean participou da comissão patrocinadora e da mesa redonda sobre "a defesa da infância contra a influência perniciosa da literatura" (CONFERÊNCIA..., 1952, p. 7). Sua participação também foi apontada no jornal Imprensa Popular, demarcando que 39 países estariam presentes na referida conferência, que trataria de "delinquência infantil, criminalidade, abrigos para menores e assistência social feminina" (PERSONALIDADES..., 1952, p. 3). Em maio, outro periódico informa que aconteceria em julho, na Europa, o Congresso Mundial de Mães e que Yvonne Jean compareceria como uma das participantes da Assembleia Nacional de Mães, pelo estado de São Paulo (CONGRESSO MUNDIAL..., 1955, p. 5).

É possível acompanhar seu desempenho em outras ocorrências na imprensa, todavia, até aqui já é possível identificar que Yvonne Jean tinha um conhecimento sobre questões relacionadas com a infância e com a educação da criança, cunhado na prática de suas participações em alguns eventos e circulado nas páginas de jornais cariocas. Quando assume a coluna no jornal Correio Braziliense, já possuía o traquejo com o debate educativo e o utiliza para apontar aspectos que considera que deviam ser enfatizados. O primeiro deles é sobre a importância do Jardim de Infância como local apropriado para a educação da criança pequena e a exigência de sua existência em Brasília:

Faltava o setor pré-primário nessa coluna dedicada a todos os estudantes do Distrito Federal. O Jardim de Infância é tão importante quanto a escola primária. Criança que passou pelo Jardim de Infância estuda de modo bem diferente de outra, que trava pela primeira vez contatos escolares ao ingressar no primeiro ano. O papel do Jardim de Infância moderno não é mais, como outrora, dar rudimentos de leitura, caligrafia e cálculo e sim preparar a criança a receber o ensino, desenvolver sua inteligência e senso artístico, habilidade manual e senso de comunidade. Muitos pais 
ainda não dão a devida importância ao jardim de infância, entretanto, devemos todos lutar para a concretização tão rápida quanto possível dos projetos dos construtores de Brasília: entre eles a criação de um jardim de infância para cada superquadra (JEAN, 1962, p. 8).

Para além da narrativa da pertinência das crianças frequentarem um jardim de infância, o pedido de criação de novas unidades em cada superquadra ${ }^{4}$ deve ser considerado de acordo com o proposto para a pré-escola no Distrito Federal e o número existente de superquadras até aquele momento. Segundo o Plano de Construções Escolares de Brasília, "como a nova capital é construída em quadras, e cada quadra abrigará população variável de 2.500 a 3.000 habitantes, foi calculada a população escolarizável para os níveis elementar e médio", sendo estabelecido que em cada quadra haveria um jardim de infância e uma escola-classe (TEIXEIRA, 1961, p. 196). Todavia, Brasília não estava totalmente construída quando foi inaugurada e inicialmente foram projetadas seis superquadras-modelos, dispostas pelo território da Asa Sul e Asa Norte.

Destaca-se que o traçado de Brasília é conhecido como um formato de avião, por isso cada lado ficou nomeado como Asa Norte e Asa Sul. Essa nomenclatura teria sido pensada pelo chefe de obra, o engenheiro Moacyr Gomes e Souza, e, segundo Augusto Guimarães Filho, "Lucio Costa não queria que as duas partes da cidade fossem chamadas de zona, o que remeteria à conotação de zona norte e zona sul que há no Rio de Janeiro" (MACHADO, 2007, p. 66). Ele ainda diz que "Lucio Costa não gostou da nova nomenclatura, porque não aprovava a comparação do Plano Piloto com um avião, meio de transporte que não apreciava", aceitando só para não refutar a colaboração do engenheiro Gomes e Souza (MACHADO, 2007, p. 67). Atualmente são 60 superquadras em cada asa, totalizando 120 superquadras (BRASÍLIA, 2015). As primeiras plantas da cidade demonstravam a existência de 49 superquadras em cada asa (Norte e Sul), ou seja, um total de 98 superquadras (MACHADO, 2007).

4 As superquadras são formadas por um conjunto residencial e comercial e foram pensadas como faixas duplas, cujas nomenclaturas são definidas em relação ao Eixo Rodoviário e ao Eixo Monumental. Inicialmente, foram projetadas seis superquadras-modelos. Seguindo o relato de Nauro Esteves, "um dos arquitetos mais atuantes no início da construção de Brasília", é "claro que há algumas [superquadras] parecidas, principalmente as construídas nos anos de 1960 e 1970" (VASQUES et al., 2015, p. 40). A Superquadra Sul (SQS) 105 e a SQS 106 foram consideradas como modelos, uma vez que nelas estão dispostos projetos de Oscar Niemeyer e Burle Marx. "Os estudos desenvolvidos sobre as primeiras plantas inventariadas expressam que o sistema de endereçamento das superquadras foi-se desenvolvendo paulatinamente" (MACHADO, 2007, p. 66). 
Retornando à década de 1960, até o final de 1962, estariam inaugurados quatro jardins de infância (o Jardim de Infância 21 de Abril, no Setor de Habitações Germinadas Sul 707 (SHIG 707)5 , o Jardim de Infância da SQS 108, o Jardim de Infância da SQS 208 e o Jardim de Infância da SQS 114). Porém, antes dessas inaugurações, é possível acompanhar a jornalista empenhada para que ocorressem:

Até agora, só construíram dois Jardins de Infância: o da Caixa Econômica e o do IPASE ${ }^{6}$. Além do mais, ambos funcionam durante quatro horas diárias. Urge, evidentemente, construir novos jardins de infância em todos os pontos da cidade, para cada grupo de 4 superquadras. Não tenho dúvidas que isto será realizado seguramente, de acordo com os planos. [...]. Propomos o lançamento da campanha "um jardim de infância para cada 4 superquadras! Todos os jardins de infância com horário integral!" É para já! (JEAN, 1962, p. 8).

O apelo pelo horário integral tensionava o disposto no Plano de Construções Escolares de Brasília, que indicava que um Jardim de Infância teria quatro salas, portanto oito turmas com vinte crianças ${ }^{7}$ e funcionaria em dois turnos, atendendo cento e sessenta crianças no total (TEIXEIRA, 1961). O que ela pedia exigiria realmente o aumento da rede de ensino voltada para a criança pequena, uma vez que cada Jardim de Infância atenderia a metade do pretendido.

Em julho ela noticia que o Jardim de Infância da SQS 114 estava pronto, esperando somente alguns móveis para anunciar a data de abertura para matrícula e funcionamento, mas acreditava que até o início de agosto as inscrições seriam feitas. Diz ainda que a iniciativa "melhorará um pouco a angustiante situação dos pais de filhos pequenos, pois três jardins para todo o Plano Piloto [...] evidentemente não podem atender às necessidades da população" (JEAN, 1962, p. 9). Ela também reforça que não bastava somente construir jardins de infância, mas era necessário mantê-los funcionando para não prejudicar as crianças, como ocorria com a reforma do Jardim de Infância 21 de Abril, da Caixa Econômica (JEAN, 1962, p. 8).

5 Hoje denominado Setor de Habitações Coletivas Sul 707 (SHCS 707).

6 Instituto de Previdência e Assistência dos Servidores do Estado.

7 Como aponta Fúlvia Rosemberg (1999, p. 15), muito do que se propôs para a educação pré-primária até 1970 se pautou nas recomendações da XXVI Conferência Internacional da Instrução Pública da Unesco (1961) e, entre essas, estava descrito que "a relação adulto-criança não deveria ultrapassar $1 / 20[\ldots]$ ". 
Muitas vezes Yvonne Jean diz que havia recebido cartas de responsáveis reclamando, então foi conferir e por isso escrevia tal solicitação em sua coluna. É possível perceber que "as causas" dos jardins de infância do Distrito Federal são defendidas pela jornalista. Nesse sentido, a vemos pedindo ou agradecendo determinadas ações que auxiliam gestoras, professoras e crianças nos jardins de infância, como fez com os pedidos de doações de caixas de ovos para as crianças fazerem carrinhos (JEAN, 1962, p. 9) ou de livros infantis (JEAN, 1962, p. 8). Fosse por ser uma recorrente publicização dos erros e entraves governamentais para com a pré-escola, ou por outros motivos da alçada política e administrativa do Distrito Federal, o leitor comum do jornal poderia sentir que seus pedidos ganhavam eco na sua coluna e que isso fortalecia, de alguma forma, a resolução das situações apontadas.

Pelo relato de Yvonne Jean é possível se aproximar das dinâmicas pedagógicas, da forma como a criança era considerada nelas e da materialidade necessária para a efetivação da educação da criança pequena em Brasília. Nesse sentido, a acompanhamos em festas juninas, celebrações diversas e formaturas nos jardins de infância, como na que teceu elogios aos estabelecimentos no Distrito Federal: "são simpáticos, alegres, bem montados"; "a maioria das professoras gosta da especialidade e segue o método moderno de aproximação da criança com o aprender a aprender" (JEAN, 1964, p. 9).

Jordana Botelho (2016, p. 230), ao tratar do perfil das professoras dos jardins de infância no Paraná, no período igual àquele em que escreve Yvonne Jean, pontua que "é possível observar um mesmo intuito de proporcionar às crianças experiências boas e criadoras no trabalho diário", com programas e propostas adequando-se aos interesses e necessidades das crianças e não o contrário. Tudo indica que a jornalista compartilhava a mesma opinião de ações pedagógicas, inclusive, incomodando-se com o que chamou de "exagero": incluir "Geometria" nos diplomas das crianças, apontando como bom exemplo o que ocorria no Jardim de Infância gaúcho, onde os pequenos eram levados a pensar de acordo com sua faixa etária, sem cobranças tão específicas de conteúdos (JEAN, 1964, p. 9). É pertinente atentar-se ao fato de que poucos meses antes, em um edital de concurso de professores, incluindo as professoras que se dirigiriam ao pré-primário, temos como tarefas das futuras docentes: "em Jardim de Infância orientar a educação artístico-plástico musical da criança, responsabilizar-se pela educação física, recreação e artes aplicadas", além da documentação de registro específica (CONCURSO..., 1964, p. 7).

Ainda sobre a questão do respeito à idade das crianças, Fúlvia Rosemberg (1999) aponta que ela comparece como uma das recomendações emanadas da XXVI Conferência Internacional da Instrução Pública da Unesco, em 1961. Yvonne Jean não se remete à referida conferência, todavia demonstra em sua coluna que às crianças deve ser dado tempo para brincadeiras, para imersão 
em atividades artísticas e literatura infantil. E, dessa forma, traz a criança para o centro de suas narrativas, tentando chamar a atenção dos adultos para a importância dos jardins de infância. Assim, ela convida seus leitores a irem ver "meninos cuidando de carros em miniaturas", feitos de caixas de papelão, no Jardim de Infância do IAPB ${ }^{8}$ (JEAN, 1963, p. 5); informa sobre o espetáculo de fantoches para crianças do Jardim de Infância da Caixa Econômica, com a peça "A cigarra e a formiga", de Silvia Orthof (JEAN, 1963, p. 9) e de como foi bom visitar o Jardim de Infância da SQS114 e ver as crianças fazendo uma apresentação de circo (JEAN, 1964, p. 7).

O protagonismo infantil ganha destaque em sua coluna quando o assunto é produção e posicionamento das crianças nos jardins de infância. Yvonne Jean chama atenção para o fato de que o Jardim de Infância do IPASE (SQS208) passou a servir merenda, sendo que "as crianças ficaram encantadas com a novidade e isso foi assunto do jornal mural" (JEAN, 1962, p. 9). Como vimos, a questão da merenda nas instituições educativas já havia sido por ela esmiuçada na I Assembleia Nacional da Mulher (1952) sendo, portanto, algo com que concordava e referendava como necessário. Mas ter em um Jardim de Infância um "jornalzinho" foi algo que mereceu outra notícia, dias depois, informando que ele foi nomeado "pelas próprias crianças, após longas discussões", como $O$ Retrato do Jardim, e que "destinava-se a aproximar os pais de alunos do jardim, descrevendo incidentes, fatos, reações, necessidades e realizações" (JEAN, 1962, p. 9).

Yvonne Jean pondera que os jornais dos jardins de infância do Distrito Federal não são parte de uma "iniciativa surrealista" e sim ajudam "os pequenos a encontrar meios de expressão de planos e atividades também para os pais", além de funcionarem como um espaço de fala dos "pequeninos" que "já fazem seu noticiário, como num jornal de gente grande!" (JEAN, 1962, p. 6). Nesse caso, a jornalista fazia menção ao jornal Cirandinha, do Jardim de Infância da SQS108.

$\mathrm{O}$ acesso a esse tipo de produção infantil infelizmente se perdeu nos arranjos e desarranjos das documentações, contudo, ficou a composição ditada por Alice Maria e Gilka Maria à professora: "Era uma vez dois gatinhos/Eles estavam com muito frio/ No varal estava um par de meias/Os gatinhos pularam dentro das meias/Os gatinhos ficaram encolhidos" (JEAN, 1962, p. 6). Outro momento transcrito pela professora foi: "A Claudia trouxe dois patinhos para visitar a sala azul", e a partir dessa informação, a própria docente narra que "a Claudia fez a biografia dos patinhos, a professora sua genealogia e peculiaridades, a turma sua refeição, e assim por diante. Foi um acontecimento para Leiliane, Elizabeth, Carla, Vânia, Gustavo e Claudia” (JEAN, 1962, p. 6). 
Possivelmente, nesse dia ou semana no referido Jardim de Infância, as crianças vivenciaram experiências com animais domésticos e situações com bichos, no geral. Acreditando que, como afirma Robert Darnton (1992, p. 200), "a leitura possui uma História", a escrita e publicização dessas palavras ditadas pelas crianças permitem interpretações históricas sobre situações, contextos, experiências do grupo que frequentava o Jardim de Infância, cujo posicionamento não nos é possível alcançar pela documentação oficial.

\section{Apontamentos finais}

Quando apresenta sua coluna pela primeira vez no jornal Correio Braziliense, Yvonne Jean faz um trocadilho com o nome dela, "Esquina de Brasília", e com o fato de que o desenho da capital não permite que se tenham esquinas. Diante desse contexto de uma cidade planejada, ela faz o seguinte convite: "querem formar esta esquina que ainda falta em Brasília para que nela nos encontremos todas as manhãs, após o café?"(JEAN, 1962, p. 9). Na sequência, escreve que estava emocionada, conta um pouco sobre o conceito de cidade moderna que estava vivenciando depois dos ares cariocas e demarca seu objetivo: "nesse sentido, queríamos dar o primeiro e principal lugar ao assunto número um do Brasil, em geral, e, particurlamente de Brasília, a cidade dos homens de amanhã: a educação" (JEAN, 1962, p. 9).

A leitura de sua coluna permite uma aproximação com o contexto educativo na capital do Brasil e, no caso aqui investigado, possibilita a identificação de questões que comparecem na pauta das solicitações ou das considerações sobre a pré-escola, tais como: acesso para todas as crianças aos jardins de infância - portanto, a necessidade de construção conforme estava no planejamento de Brasília; manutenção das unidades criadas; acompanhamento das práticas dispensadas às crianças e o destaque para a capacidade dos pequenos e seu desenvolvimento potencial ao frequentar o Jardim de Infância.

As possibilidades de temas e debates sobre a pré-escola, a partir do olhar de Yvonne Jean, aqui não se esgotam. Entretanto, faz-se o destaque para a representação social de sua coluna, determinada também pelos interesses do grupo/jornal que a contratou. A partir das discussões que propõe, das reflexões e convites, da exposição do seu ponto de vista e dos impasses é possível apontar a existência de lutas de representação, que, conforme explicita Roger Chartier (1988, p. 17), têm "tanta importância como as lutas econômicas para compreender os mecanismos pelos quais um grupo se impõe ou tenta impor a sua concepção de mundo social, os valores que são os seus e o seu domínio". 


\section{REFERÊNCIAS}

ASPECTOS da Literatura Infantil. Entrega do Prêmio S. A. P. S. A Manhã, Rio de Janeiro, 18 nov. 1952, p. 2.

BOTELHO, Jordana Stella. Docência para os Jardins de Infância nas proposições de 1950 e 1963 no Estado do Paraná. In: FRANÇA, Franciele Ferreira; SILVA, Carolina R. C. da; SACRAMENTO, Cristina Carla (org.). História da educação, infância e cultura material: estudos produzidos por grupos de pesquisa da UDESC, UFPR e UNICAMP. Curitiba: CRV, 2016.

BRAGA, Aline Moraes Costa. (Im)possíveis Brasílias: os projetos apresentados no concurso do Plano Piloto da nova capital federal. São Paulo: Alameda, 2011.

BRASÍLIA. Portaria n ${ }^{\circ}$ 103/B, de 30 de abril de 1959. Cria o Departamento de Difusão Cultural da NOVACAP. Atos Normativos da FEDF (Fundação Nacional do Distrito Federal), Brasília, DF, p. xi, 1981.

BRASÍLIA. Decreto no 47.472, de 22 de dezembro de 1959. Institui a Comissão de Administração de Sistema Educacional. Atos Normativos da FEDF (Fundação Nacional do Distrito Federal), Brasília, DF, p. XIV, 1981.

BRASÍLIA. Decreto n ${ }^{\circ}$ 47.832-A, de 4 de março de 1960. Institui a Fundação Educacional de Brasília. Atos Normativos da FEDF (Fundação Nacional do Distrito Federal), Brasília, DF, p. XV, 1981.

BRASÍLIA. Estatuto da Fundação Educacional do Distrito Federal (FEDF), de 2 de julho de 1960. Atos Normativos da FEDF (Fundação Nacional do Distrito Federal), Brasília, DF, p. XVIII, 1981.

BRASÍLIA. Jardins de Infância da Rede Oficial do Distrito Federal. Os Jardins de Infância no D. F. Brasília: Fundação Educacional do Distrito Federal, 1972.

BRASÍLIA. Dados históricos do ensino oficial do Distrito Federal. Atos Normativos da FEDF (Fundação Nacional do Distrito Federal), Brasília, DF, p. xxix, 1981.

CHAHIN, Samira Bueno. Cidade nova, escolas novas? Anísio Teixeira, arquitetura e educação em Brasília. Tese (Doutorado em Arquitetura) - Faculdade de Arquitetura e Urbanismo,Universidade de São Paulo, São Paulo, 2018.

CHARTIER, Roger. A história cultural entre práticas e representações. Lisboa: DIFEL, 1988.

CONCURSO de professores. Edital. Correio Braziliense, Brasília, 6 fev. 1964, p. 7.

CONFERÊNCIA Internacional de Defesa da Infância. O Momento Feminino, Rio de Janeiro, ano II, n. 2, edição 0092(1), abr./maio 1952, p. 7.

CONGRESSO Mundial de Mães. O Jornal, Rio de Janeiro, 14 maio 1955, p. 5. 
CONGRESSO Nacional de Intelectuais em Goiás. Imprensa Popular, Rio de Janeiro, 20 nov. 1953, p. 3.

CUNHA, Ari. Visto, lido e ouvido. Correio Braziliense, Brasília, 10 jul. 1964, p. 3.

DARNTON, Robert. História da Leitura. In: BURKE, Peter (org.). A escrita da história: novas perspectivas. Tradução: Magda Lopes. 2. ed. São Paulo: Editora da UNESP, 1992. p. 199-236.

ESQUINA de Brasília. Arquivo Público do Distrito Federal, jan./jun. 1962. Localização: YJ-PI-1-A-001.

FERREIRA, Jorge. O governo Goulart e o golpe civil-militar de 1964. In: FERREIRA, Jorge; DELGADO, Lucilia de Almeida Neves (org.). O tempo da experiência democrática: da democratização de 1945 ao golpe civil-militar de 1964: Terceira República (1945-1964). Rio de Janeiro: Civilização Brasileira, 2019. p. 403-468. (Coleção O Brasil Republicano, v. 3).

FERREIRA, Jorge; GOMES, Angela de Castro. 1964: O golpe que derrubou um presidente, pôs fim ao regime democrático e instituiu a Ditadura Militar no Brasil. Rio de Janeiro: Civilização Brasileira, 2014.

FICO, Carlos. O Golpe de 1964: momentos decisivos. Rio de Janeiro: FGV, 2014.

FORMATURA nos Jardins de Infância. Correio Braziliense, Brasília, 9 dez. 1964, p. 9.

FORME sua Biblioteca. Os Tucanos na Floresta. Livro de Yvonne Jean. Sesinho, Rio de Janeiro, 1955, p. 19.

FOSTER, Josephine C.; HEADLEY, Neith E. Jardim de Infância: princípios gerais. Direção de atividades. Tradução: Daisy R. Wyllie. Rio de Janeiro: Editora Ao Livro Técnico, 1967.

FUNDAÇÃO Cultural. Correio Braziliense, Brasília, 26 abr. 1963, p. 9.

GINZBURG, Carlo. Sinais: raízes de um paradigma indiciário. In: GINZBURG, Carlo. Mitos, emblemas, sinais: morfologia e história. 1. reimp. São Paulo: Companhia das Letras, 1990.

I ASSEMBLEIA Nacional da Mulher. Diário Carioca, Rio de Janeiro, 8 nov. 1952, p. 12.

JARDIM de Infância do Instituto de Aposentadoria e Pensões dos Bancários (IAPB). Correio Braziliense, Brasília, 6 jun. 1962, p. 9.

JEAN, Yvonne. Começando o dia. Correio Braziliense, Brasília, 19 jan. 1962, p. 9.

JEAN, Yvonne. Jardim de Infância 108. Correio Braziliense, Brasília, 8 jun. 1962, p. 8.

JEAN, Yvonne. Cirandinha. Correio Braziliense, Brasília, 28 jun. 1962, p. 6.

JEAN, Yvonne. Jardim 114. Esquina de Brasília. Correio Braziliense, Brasília, 29 jul. 1962 , p. 9. 
JEAN, Yvonne. Jardim de Infância 208. Correio Braziliense, Brasília, 7 set. 1962, p. 9. JEAN, Yvonne. Jornalzinho. Correio Braziliense, Brasília, 20 set. 1962, p. 9.

JEAN, Yvonne. Jardim de Infância 114. Correio Braziliense, Brasília, 19 ago. 1964, p. 7.

KRAMER, Sonia. A política do pré-escolar no Brasil: a arte do disfarce. São Paulo: Cortez, 1992.

KUHLMANN JR., Moysés. Os intelectuais na educação da infância. In: NEPOMUCENO, Maria de Araújo; TIBALI, Elianda Figueiredo Arantes (org.). A educação e seus sujeitos na história. Belo Horizonte: ARGVMENTVM, 2007. p. 100-119.

KUHLMANN JR., Moysés. Relações sociais, intelectuais e educação da infância na História. In: SOUZA, Gizele (org.). Educar na infância: perspectivas histórico-sociais. São Paulo: Contexto, 2010. p. 81-97.

LACERDA, Nair. Problema que exige solução. Revista do Professor, São Paulo, n. 22, p. 9, nov. 1954 .

MACHADO, Marília Pacheco. Superquadra: pensamento e prática urbanística. Dissertação (Mestrado em Arquitetura) - Programa de Pós-Graduação de Arquitetura e Urbanismo, Universidade de Brasília, Brasília, 2007.

MAIS de 500 mil crianças morrem antes dos 5 anos. Manifesto divulgado pela I Assembleia Nacional de Mulheres. Diário Carioca, Rio de Janeiro, 18 nov. 1952, p. 12.

NO JARDIM de Infância. Correio Braziliense, Brasília, 27 set. 1963, p. 7.

OBRAS no Jardim de Infância estão prejudicando as aulas. Correio Braziliense, Brasília, $1^{\circ}$ maio 1962, p. 8.

O ENSINO Dia a Dia. Correio Estudantil. Correio Braziliense, Brasília, 5 jun. 1962, p. 8.

ONTEM E HOJE. Programa para crianças "Reino da Alegria”. A Noite, Rio de Janeiro, 21 out. 1955 .

PEREIRA, Eva W.; ROCHA, Lúcia Maria F. Anísio Teixeira e o plano educacional de Brasília. In: PEREIRA, Eva W. et al. (org.). Nas Asas de Brasília: memórias de uma utopia educativa (1956-1984). Brasília: Universidade de Brasília, 2011. p. 27-45.

PERSONALIDADES de 39 países na Conferência de Defesa da Infância. Imprensa Popular, Rio de Janeiro, 20 abr. 1952.

PUBLICAÇÕES Infantis. "Joãozinho no País das Sobremesas". Diário Carioca, Rio de Janeiro, 30 dez. 1951, p. 1.

REVELAÇÕES sobre o sistema Norte Americano. Flan: o jornal da semana, Rio de Janeiro, edição 22 (1), 1953, p. 12.

ROSEMBERG, Fúlvia. Expansão da educação infantil e processos de exclusão. Cadernos de Pesquisa, São Paulo, n. 107, p. 7-40, jul. 1999. 
SILVA, Ernesto. História de Brasília. Brasília: Senado Federal, 1985.

SILVA, Rafael Pereira da. Fragmentos de (auto)imagem: notas sobre o Fundo Yvonne Jean no Arquivo Público no Distrito Federal (1911-1981). Revista Maracanan, Rio de Janeiro, n. 20, p. 171-184, jan./abr. 2019.

TEIXEIRA, Ana Paula Tavares. Uma cosmopolita nos trópicos: a trajetória de Yvonne Jean no jornalismo carioca (1940-1950). Dissertação (Mestrado Bens Culturais e Projetos Sociais) - Programa de Pós-Graduação em História, Política e Bens Culturais, Escola de Ciências Sociais da Fundação Getulio Vargas Rio de Janeiro, 2018.

TEIXEIRA, Anísio. Plano de construções escolares de Brasília. Revista Brasileira de Estudos Pedagógicos, Rio de Janeiro, v. 35, n. 81, p. 195-199, jan./mar. 1961.

VASQUES, Claudia Marina et al. Superquadras de Brasília: entre escalas e conceitos. In: REIS, Carlos Madson; RIBEIRO, Sandra Bernardes; PINTO, Francisco Ricardo Costa (coord./org.). Superquadra de Brasília: preservando um lugar de viver. Brasília, DF: Instituto do Patrimônio Histórico e Artístico Nacional (IPHAN): Superintendência do Iphan no Distrito Federal, 2015. p. 24-49.

VIEIRA, Lívia M. F. A formação do profissional da educação infantil no Brasil no contexto da legislação, das políticas e da realidade do atendimento. Pro-Posições, Campinas, v. 10, n. 1, p. 28-39, mar. 1999.

Texto recebido em 21/07/2020.

Texto aprovado em 18/03/2021. 